\title{
Ventricular Electrical Heterogeneity in Experimental Diabetes Mellitus: Effect of Myocardial Ischemia
}

\author{
K. A. SEDOVA ${ }^{1,2}$, M. A. VAYKSHNORAYTE ${ }^{2}$, A. O. OVECHKIN ${ }^{2,3}$, P. KNEPPO ${ }^{1}$, \\ O. G. BERNIKOVA ${ }^{2,3}$, V. A. VITYAZEV ${ }^{2,3}$, J. E. AZAROV ${ }^{2,3}$
}

${ }^{1}$ Department of Biomedical Technology, Faculty of Biomedical Engineering, Czech Technical University, Kladno, Czech Republic, ${ }^{2}$ Laboratory of Cardiac Physiology, Institute of Physiology, Komi Science Center, Ural Branch, Russian Academy of Sciences, Syktyvkar, Russia, ${ }^{3}$ Department of Physiology, Medical Institute of Pitirim Sorokin Syktyvkar State University, Syktyvkar, Russia

Received August 4, 2015

Accepted January 19, 2016

On-line April 12, 2016

\section{Summary}

Aims of the study were to compare the development of electrocardiographic responses of the ischemia-induced heterogeneities of activation and repolarization in the ventricular myocardium of normal and diabetic animals. Body surface ECGs and unipolar electrograms in 64 epicardial leads were recorded before and during $20 \mathrm{~min}$ after the ligation of the left anterior descending artery in diabetic (alloxan model, 4 weeks, $n=8$ ) and control $(n=8)$ rabbits. Activation times (ATs), end of repolarization times (RTs) and repolarization durations (activation-recovery intervals, ARIs) were determined in ischemic and periischemic zones. In contrast to the controls, the diabetic rabbits demonstrated the significant prolongation of ATs and shortening of ARIs $(P<0.05)$ during ischemia in the affected region resulting in the development and progressive increase of the ARI and RT gradients across the ischemic zone boundary. The alterations of global and local dispersions of the RTs in diabetics correlated with the $T_{\text {peak }}-T_{\text {end }}$ interval changes in the limb leads ECGs. In the ischemic conditions, the diabetic animals differed from the controls by the activation delay, significant repolarization duration shortening, and the increase of local repolarization dispersion; the latter could be assessed by the $T_{\text {peak }}-T_{\text {end }}$ interval measurements in the body surface ECGs.

\section{Key words}

Cardiac electrophysiology • Diabetes mellitus • Regional ischemia

- Myocardium • Electrocardiography

\section{Corresponding author}

K. A. Sedova, Department of Biomedical Technology, Faculty of Biomedical Engineering, Czech Technical University in Prague, Sítná sq. 3105, 27201 Kladno, Czech Republic. E-mail: ksenia.sedova@fbmi.cvut.cz

\section{Introduction}

The excessive myocardial electrical heterogeneity dictates the level of electrical instability of the heart, whereas the myocardial ischemia is a major event exacerbating electrical inhomogeneities and leading to malignant ventricular arrhythmias. Clinical studies have found that diabetes mellitus (DM) enhances the risk of ventricular tachyarrhythmias and mortality in acute myocardial infarction even more (Cho et al. 2002, Dziewierz et al. 2010, Sanjuan et al. 2011). On the other hand, experimental studies of diabetic hearts demonstrated either the increased (Hekimian et al. 1985, Bakth et al. 1986, Wang et al. 2012) or decreased (Kusama et al. 1992, Ravingerová et al. 2000, Galagudza et al. 2007, Matejíková et al. 2008) susceptibility to ventricular arrhythmias in ischemic conditions. Spooner (2008) pointed out that DM while worsening the longterm prognosis does not affect the susceptibility to ventricular arrhythmias in acute settings in patients with cardiovascular diseases. Some clinical observations suggested that the susceptibility to ventricular arrhythmias could be related to concomitant factors such 
as hypoglycemic episodes or medication (Chow et al. 2014, Curione et al. 2014, Pistrosch et al. 2015). These conflicting data on the electrical stability of the heart in diabetes mellitus under ischemia suggest that the diabetic myocardium may have a specific electrophysiological response to the ischemic insult.

The diabetic cardiomyopathy is associated with the electrophysiological alterations in the myocardium. The DM-related changes in the cardiac electrical properties, specifically the prolongation of action potential durations, have been well documented at the cellular level (Magyar et al. 1992, Zhang et al. 2007, Lengyel et al. 2008, Gallego et al. 2009). Equally important would be largely lacking thus far data on the distribution of the electrophysiological properties throughout the myocardium and its dynamical changes in ischemia. This spatiotemporal electrical pattern is quantitated as a dispersion of repolarization that is, in turn, attempted to be assessed by ECG. For this purpose, several ECG indices were considered, including $T_{\text {peak }}-T_{\text {end }}$ interval, a promising index for the estimation of the dispersion of repolarization. Clinical investigations either supported (Panikkath et al. 2011, Hetland et al. 2014, Mozos 2015) or opposed (Smetana et al. 2011, Porthan et al. 2013) to its prognostic utility suggesting that electrophysiological information content of $T_{\text {peak }}-T_{\text {end }}$ interval could vary in different conditions. $T_{\text {peak }}-T_{\text {end }}$ interval has been also tested in diabetic patients (Clemente et al. 2012, Miki et al. 2014). However, the behavior of the $T_{\text {peak }}-T_{\text {end }}$ and its relation to the dispersion of repolarization in an arrhythmogenic stress conditions, such as myocardial ischemia, is largely unknown in the setting of DM.

The objective of the present study was to compare the ischemia-induced changes of ventricular epicardial activation and repolarization patterns and their expressions in the parameters of the body surface ECGs in normal and diabetic rabbit hearts.

\section{Methods}

The experiments were carried out in adult Chinchilla rabbits (age from 7 to 9 months, body mass from 2.9 to $3.3 \mathrm{~kg}$ ). The investigation conformed to the Guide for the Care and Use of Laboratory Animals (2011). Experimental type $1 \mathrm{DM}$ was induced in 8 animals ( 5 females) by a single intravenous alloxan injection ( $120 \mathrm{mg} / \mathrm{kg}$ body mass, 4 weeks follow-up), and 8 healthy animals (4 females) served as controls. DM was confirmed by at least double determinations of fasting venous blood glucose level more than $7 \mathrm{mmol} / 1$ with OneTouch glucometer (LifeScan Inc, USA). The openheart experiments were consistently done during the daytime hours (from 11-00 to 13-00) on the animals anesthetized with zoletil $(15 \mathrm{mg} / \mathrm{kg}$ body mass, intramuscular injection), intubated and mechanically ventilated. The heart was exposed by a midsternal incision. The temperature of the heart was maintained at $37-38^{\circ} \mathrm{C}$ by the irrigation with warm saline and warming the room air. An electrode sock with 64 leads $(3-5 \mathrm{~mm}$ interelectrode distance) was placed on the ventricular surface, and the unipolar electrograms were simultaneously recorded in reference to Wilson's terminal at spontaneous sinus rhythm. The data acquisition was done using a custom-designed mapping system (16 bits; bandwidth 0.05 to $1000 \mathrm{~Hz}$; sampling rate $4000 \mathrm{~Hz}$ ).

Electrograms were recorded in the baseline and in the course of 20-min ischemia, which was produced by the ligation of the left anterior descending coronary artery (LAD). Evans blue dye (Sigma-Aldrich $\mathrm{GmbH}$, Germany, $0.5 \%$ ) was injected postmortemly into the aorta. The ischemic zone was determined by the absence of Evans blue perfusion, and its size was estimated as the area of the figure circumscribed by the leads on the border of the ischemic zone.

Limb lead ECGs were monitored in the course of the experiment, and the QRS and QT durations were measured in the limb lead II. The corrected QT interval was calculated by the equation $\mathrm{QTc}=\mathrm{QT}-0.175 \times(\mathrm{RR}-300)$ (Carlsson et al. 1993). The total duration of the $T_{\text {peak }}-T_{\text {end }}$ interval was measured as a period between the earliest $\mathrm{T}_{\text {peak }}$ and the latest $\mathrm{T}_{\text {end }}$ in the limb leads. In each epicardial lead, the activation time (AT) and the end of repolarization time (RT) were determined as $d V / d_{\text {min }}$ during the QRS complex and $\mathrm{dV} / \mathrm{dt}_{\max }$ during the $\mathrm{T}$ wave, respectively (Coronel et al. 2006). The activationrecovery interval (ARI) serving as a measure of local repolarization duration was measured as the difference between the RT and AT. The averaged values of these variables were calculated for different myocardial regions and specifically for the ischemic zone and the adjacent 3 to $5 \mathrm{~mm}$ width band of perfused myocardium referred to as a periischemic zone. The differences in the ATs, ARIs, and RTs between the ventricular regions were referred to as gradients (e.g. boundary gradient) and the difference between the earliest and the latest RT values throughout the ventricular epicardium was referred to as 
the dispersion of repolarization.

Statistical analysis was performed with the SPSS 11.5 software packages. The data are given as medians and interquartile intervals. Wilcoxon test and Fridman test with Dunnett post-hoc procedure were utilized for the single and multiple comparisons within the groups, respectively. Mann-Whitney U-test was used to compare different groups of animals. The correlation between epicardial mapping indices and ECG parameters was evaluated with Spearman rank correlation test as the evaluated parameters were not normally distributed. The differences were considered significant at $\mathrm{P}<0.05$.

\section{Results}

The control and DM groups matched with each other for sex, age, body mass and heart to body mass ratio. As expected, the glycemia level was significantly higher in diabetic animals as compared to controls [15.3 $(8.8 ; 20.0) \mathrm{mmol} / \mathrm{l}$ vs. $5.9(5.7 ; 6.3) \mathrm{mmol} / \mathrm{l}$, respectively, $\mathrm{P}<0.01] . \mathrm{RR}, \mathrm{QT}, \mathrm{QTc}$ and $\mathrm{T}_{\text {peak }}-\mathrm{T}_{\text {end }}$ intervals were longer in animals with DM, whereas the QRS duration was similar in both groups (Table 1). The epicardial AT sequences in normals and diabetics were similar and directed from the left ventricular (LV) apex to the LV base and from the right ventricular (RV) free wall to the LV free wall. The spatial distribution of RTs was relatively uniform in healthy animals and heterogeneous in diabetics. In the latter group, the RV RTs were longer than the LV RTs [DM: $134(119 ; 142)$ ms vs. 106 (104; 114) ms, $\mathrm{P}=0.012$; Control: 115 (106; 127) ms vs. $114(99 ; 119) \mathrm{ms}, \mathrm{P}>0.05$, respectively].

Table 1. ECG parameters in rabbits of control and DM groups [Median and interquartile intervals ( $25 \%, 75 \%)$ ].

\begin{tabular}{|c|c|c|c|c|c|c|}
\hline & & RR, ms & QRS, ms & QT, ms & QTe, ms & $\mathbf{T}_{\text {peak - }} \mathbf{T}_{\text {end }}, \mathbf{m s}$ \\
\hline \multirow[t]{3}{*}{ Baseline } & control & $\begin{array}{c}230 \\
(220 ; 247)\end{array}$ & $\begin{array}{c}33 \\
(31 ; 36)\end{array}$ & $\begin{array}{c}159 \\
(147 ; 160)\end{array}$ & $\begin{array}{c}163 \\
(159 ; 171)\end{array}$ & $\begin{array}{c}41.5 \\
(39 ; 45)\end{array}$ \\
\hline & $D M$ & $\begin{array}{c}269 \\
(249 ; 282)\end{array}$ & $\begin{array}{c}32 \\
(30 ; 35)\end{array}$ & $\begin{array}{c}182 \\
(171 ; 186)\end{array}$ & $\begin{array}{c}188 \\
(180 ; 190)\end{array}$ & $\begin{array}{c}49 \\
(46 ; 68)\end{array}$ \\
\hline & $P$ & 0.03 & $\mathrm{~ns}$ & 0.003 & 0.009 & 0.04 \\
\hline \multirow[t]{3}{*}{$10^{`}$ ischemia } & control & $\begin{array}{c}229 \\
(209 ; 247)\end{array}$ & $\begin{array}{c}34 \\
(30 ; 38)\end{array}$ & $\begin{array}{c}147 \\
(139 ; 171)\end{array}$ & $\begin{array}{c}160 \\
(153 ; 180)\end{array}$ & $\begin{array}{c}49 \\
(43 ; 60)\end{array}$ \\
\hline & $D M$ & $\begin{array}{c}252 \\
(239 ; 264)\end{array}$ & $\begin{array}{c}32 \\
(31 ; 36)\end{array}$ & $\begin{array}{c}160^{*} \\
(151 ; 169)\end{array}$ & $\begin{array}{c}170^{*} \\
(160 ; 175)\end{array}$ & $\begin{array}{c}47 \\
(43 ; 53)\end{array}$ \\
\hline & $P$ & $\mathrm{~ns}$ & ns & ns & ns & ns \\
\hline \multirow[t]{3}{*}{$20^{`}$ ischemia } & control & $\begin{array}{c}225 \\
(205 ; 240)\end{array}$ & $\begin{array}{c}33 \\
(31 ; 39)\end{array}$ & $\begin{array}{c}147 \\
(134 ; 166)\end{array}$ & $\begin{array}{c}160 \\
(151 ; 177)\end{array}$ & $\begin{array}{c}38.5 \\
(31 ; 52)\end{array}$ \\
\hline & $D M$ & $\begin{array}{c}252 \\
(243 ; 267)\end{array}$ & $\begin{array}{c}33 \\
(30 ; 38)\end{array}$ & $\begin{array}{c}155^{*} \\
(148 ; 168)\end{array}$ & $\begin{array}{c}164^{*} \\
(157 ; 173)\end{array}$ & $\begin{array}{c}50.5 \\
(37 ; 54)\end{array}$ \\
\hline & $P$ & ns & ns & ns & ns & $\mathrm{ns}$ \\
\hline
\end{tabular}

* $\mathrm{P}<0.05$ vs. baseline; $\mathrm{DM}$, diabetes mellitus; $\mathrm{ns}$, nonsignificant.

The size of the ischemic area was similar in the diabetic and control animals $\left[75.6(56.5 ; 86.0) \mathrm{mm}^{2}\right.$ vs. $55.3(42.4 ; 63.5) \mathrm{mm}^{2}$, for control and DM animals, respectively, $\mathrm{P}>0.05]$. Isolated premature ventricular beats were sporadically observed in both groups. During ischemia, the QT and QTc intervals shortened in the DM group (Table 1). Coronary occlusion induced changes in electrograms recorded from the ischemic zone (Fig. 1), but the alterations found in this area differed in the control and diabetic animals (Fig. 2). The statistically significant activation delay in the ischemic zone was found only in diabetics $(\mathrm{P}<0.05)$. At 20 -min of coronary occlusion, there were no statistically significant effects on ARIs in the control group. At least in part, this could be ascribed to variable individual profiles of ARI changes in the control group, which demonstrated either ARI shortening or prolongation, while the consistent shortening was found in the DM group (Fig. 3). 


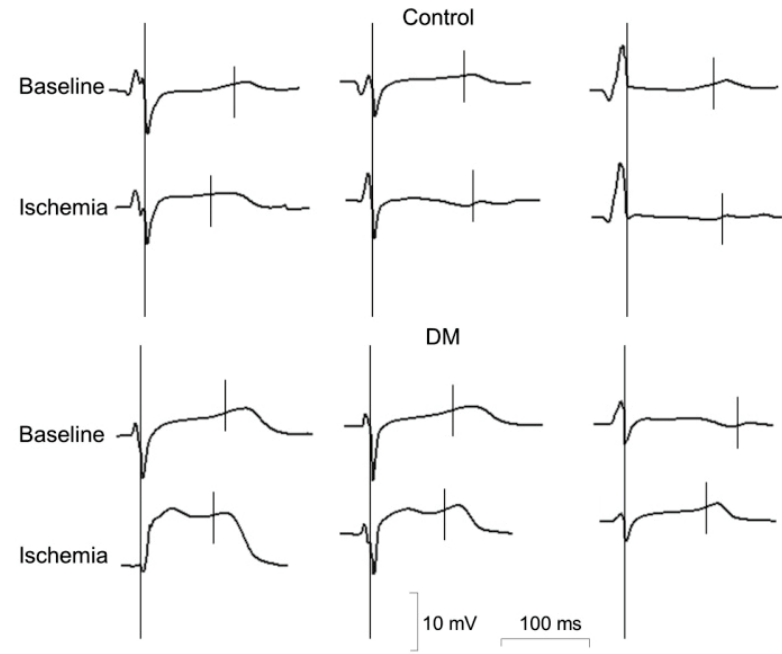

Fig. 1. Representative electrograms led across the ischemic zone in the apical third of the anterior left ventricle in the control and diabetic rabbits. Electrograms in baseline and ischemia are aligned by the activation times (AT, long vertical bars) and the end of repolarization times (RT) are indicated by the short vertical bars. See nonuniform changes of ARIs (RT-AT differences) in the control animals in ischemia.
Ischemia induced the development of specific epicardial activation and repolarization patterns (Fig. 4) characterized by the abrupt spatial differences in ATs and RTs corresponding to the area of ischemia (Fig. 4). Such differences were more pronounced in the DM group as compared to controls. The substantial ARI shortening in diabetics resulted in the development of a boundary ARI and RT gradients between the ischemic and adjacent periischemic zones, which progressively increased during the ischemic episode (Table 2). A significant correlation was found between the $T_{\text {peak }}-T_{\text {end }}$ interval duration and the global RT dispersion in the diabetic rabbits under 20-min ischemia $(\mathrm{r}=0.86, \mathrm{P}=0.007)$. In turn, the global $\mathrm{RT}$ dispersion was associated with the magnitude of the boundary RT gradient $(\mathrm{r}=0.857, \mathrm{P}=0.007)$ which accordingly explains the correlation between the $\mathrm{T}_{\text {peak }}-\mathrm{T}_{\text {end }}$ interval duration and the boundary $\mathrm{RT}$ gradient found only in the DM group ( $\mathrm{r}=0.714, \mathrm{P}=0.047)$.
Control

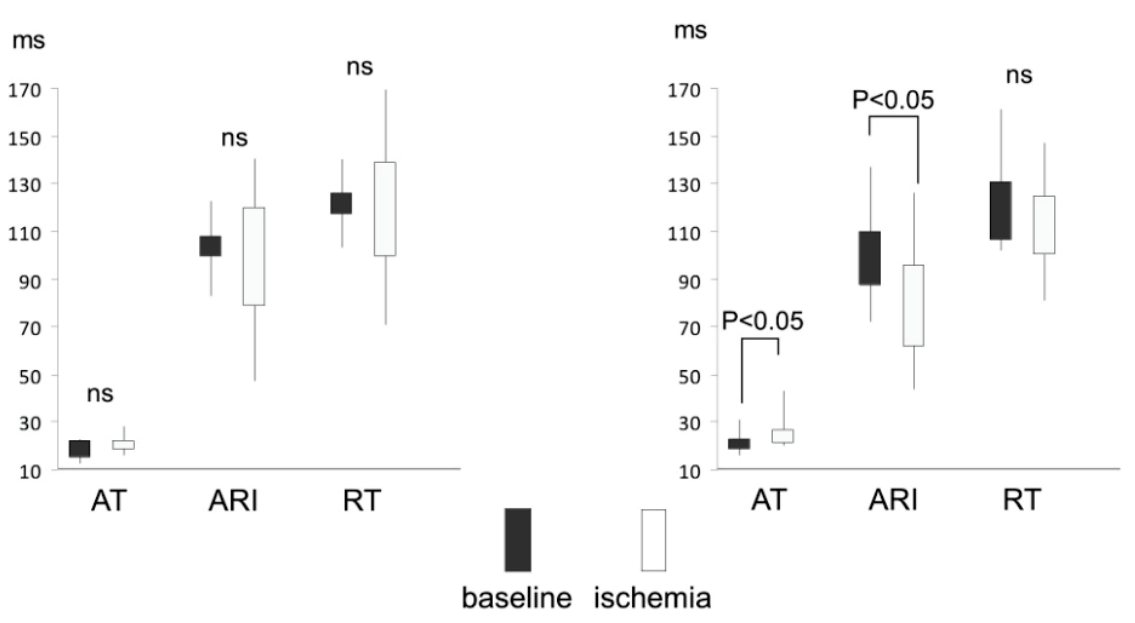

Fig. 2. The changes of the activation times (AT), activation-recovery intervals (ARI) and end of repolarization times (RT) in the ischemic zone in the control and DM groups. Boxes and bars identify the interquartile intervals and maximal and minimal values, respectively.

Table 2. The changes of activation time gradients, activation recovery interval gradients and end of repolarization time gradients between ischemic and periischemic $(\mathrm{i} / \mathrm{p})$ myocardium in control and DM groups [Median and interquartile intervals $(25 \%, 75 \%)$ ].

\begin{tabular}{|c|c|c|c|c|c|c|}
\hline & \multicolumn{3}{|c|}{ Control } & \multicolumn{3}{|c|}{ DM } \\
\hline & $\begin{array}{c}\mathrm{AT} \mathrm{i} / \mathrm{p} \\
\text { gradients }\end{array}$ & $\begin{array}{c}\text { ARI i/p } \\
\text { gradients }\end{array}$ & $\begin{array}{c}\mathrm{RT} i / p \\
\text { gradients }\end{array}$ & $\begin{array}{c}\mathrm{AT} \mathrm{i} / \mathrm{p} \\
\text { gradients }\end{array}$ & $\begin{array}{c}\text { ARI } \mathrm{i} / \mathrm{p} \\
\text { gradients }\end{array}$ & $\begin{array}{c}\mathrm{RT} \mathrm{i} / \mathrm{p} \\
\text { gradients }\end{array}$ \\
\hline $\begin{array}{l}\text { Baseline (future } \\
\text { ischemic zone) }\end{array}$ & $0.24(-2.1 ; 0.8)$ & $5.1(0.1 ; 13.2)$ & $5.5(-1.2 ; 12.1)$ & $-0.3(-1.0 ; 0.4)$ & $\begin{array}{c}0.45 \\
(-3.0 ; 2.4)\end{array}$ & $\begin{array}{c}-0.98 \\
(-3.6 ; 0.9)\end{array}$ \\
\hline $1 `$ ischemia & $-0.27(-1.1 ; 1.8)$ & $2.8(-2.2 ; 7.6)$ & $3.0(-2.8 ; 13.1)$ & $0.5(-0.3 ; 0.6)$ & $\begin{array}{c}-14.8 \\
(-21.3 ;-6.7) \dagger\end{array}$ & $\begin{array}{c}-15.3 \\
(-22.4 ;-5.6) \dagger\end{array}$ \\
\hline 10`ischemia & $0.4(-1.0 ; 2.5)$ & $0.6(-12.5 ; 6.0)$ & $0.02(-9.8 ; 7.9)$ & $1.7(0.4 ; 2.9)$ & $\begin{array}{c}-20.0 \\
(-29.6 ;-16.9)^{*} \dagger\end{array}$ & $\begin{array}{c}-22.8 \\
(-24.1 ;-11.2)^{* \dagger}\end{array}$ \\
\hline $20^{`}$ ischemia & $0.4(-0.7 ; 2.6)$ & $-1.2(-12.2 ; 4.3)$ & $-0.7(-10.1 ; 3.6)$ & $1.7(0.5 ; 2.7)$ & $\begin{array}{c}-25.3 \\
(-32.4 ;-4.3)^{*} \dagger\end{array}$ & $\begin{array}{c}-24.5 \\
(-28.6 ;-4.5)\end{array}$ \\
\hline
\end{tabular}

$* \mathrm{p}<0.05$ for Dunnett post-hoc test (vs. baseline), $+\mathrm{p}<0.05$ for Mann-Whitney (vs. control). 

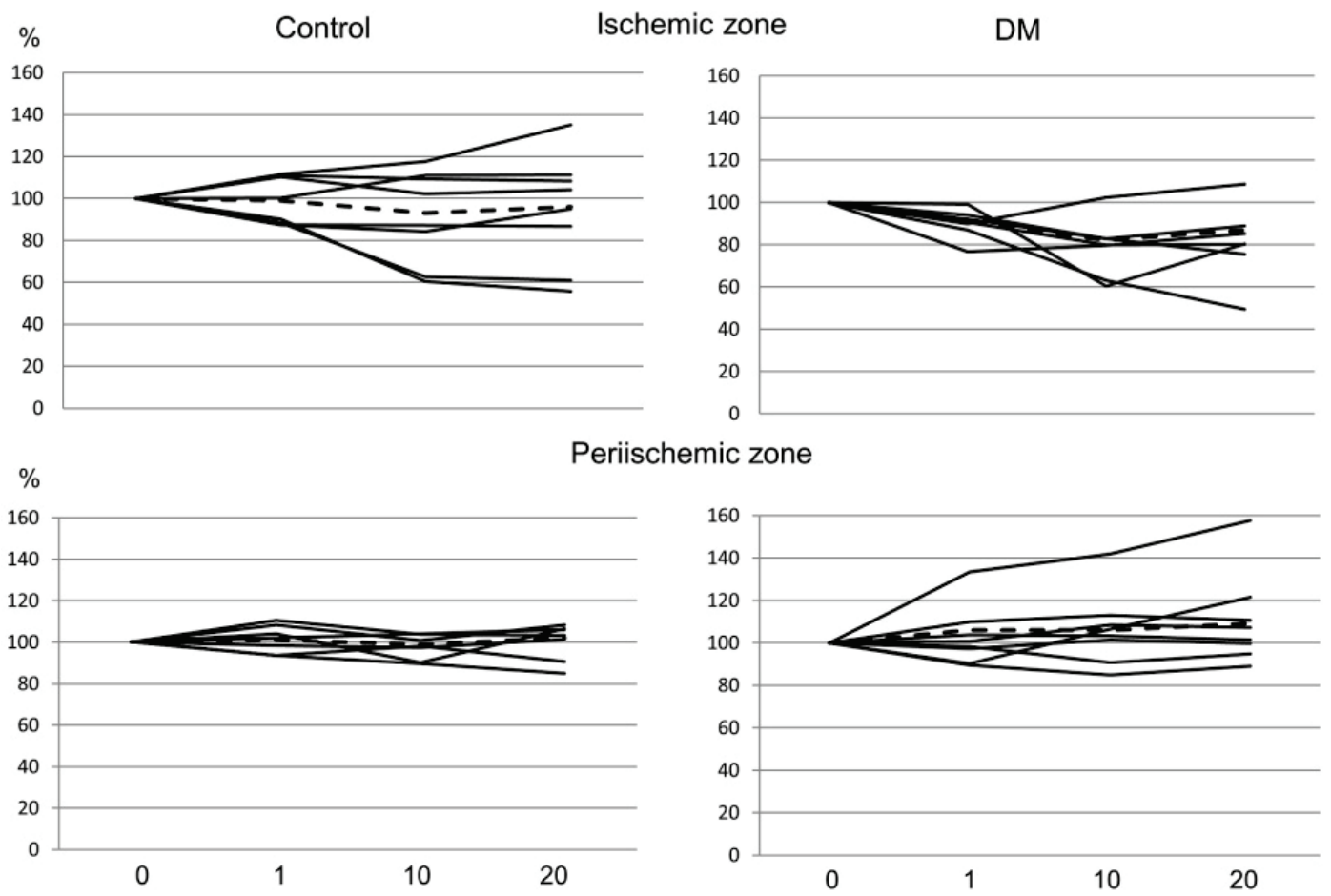

Duration of ischemia, min

Fig. 3. Individual ARI changes (\%) in the periischemic and ischemic zones during the ischemic episode in the control and diabetic animals. The baseline value is $100 \%$. Dashed lines identify for the means.
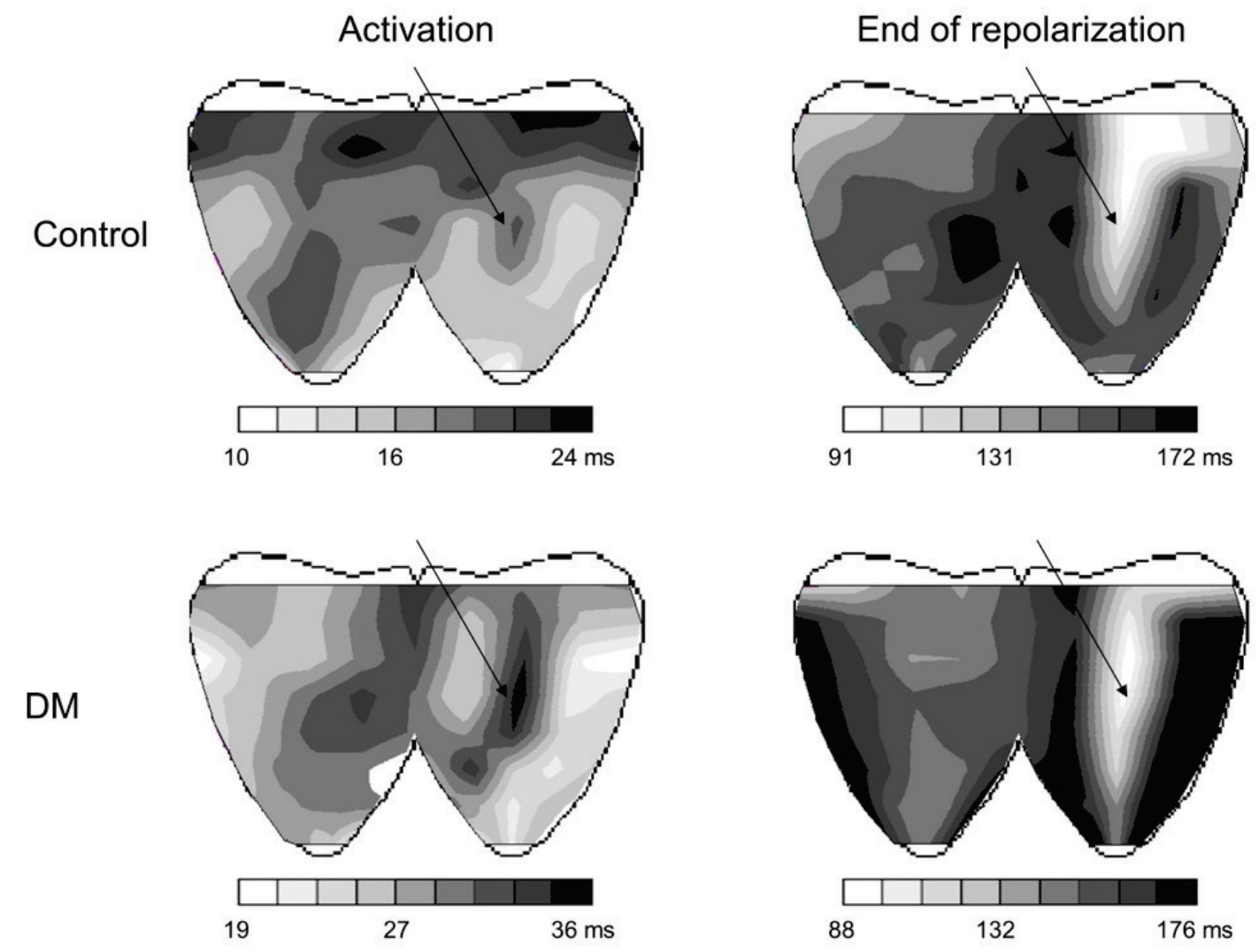

Fig. 4. Representative isochronal maps of activation and end of repolarization times in the control and diabetic animals at 20 min of coronary occlusion that produced the regional ischemia (arrows). Numbers on the scales indicate the time elapsed from the QRS onset. The left, and right sides of each map correspond to the anterior and posterior surfaces of the ventricles, respectively. The greater contrast and "denser" isochrones at the margins of ischemic area demonstrates the greater effects ischemia produced in the diabetic animals. DM, diabetes mellitus. 


\section{Discussion}

The prolonged QTc found in the diabetic rabbits is consistent with our previous observations (Vaykshnorayte et al. 2012, Ovechkin et al. 2015) and data obtained in other animal species (Howarth et al. 2011) or humans (Žákovičová et al. 2014). This suggested that the average ventricular repolarization duration prolonged, presumably due to the downregulation of potassium repolarizing currents (Magyar et al. 1992, Zhang et al. 2007, Lengyel et al. 2008, Gallego et al. 2009). The observed interventricular RT difference implied that the action potential duration lengthening should be heterogeneous in ventricular myocardium and be predominantly expressed in the RV at least at 1-month follow-up from the DM induction. Likewise, the shortening of QT and QTc during the ischemic exposure was consistent with the repolarization duration shortening in the DM group.

During ischemia, ATs and ARIs did not change significantly in the control group, and the marked interindividual variations in the ischemia-induced ARI response were observed. It is noteworthy that several control animals demonstrated the prolongation of ARIs. Verkerk et al. (1996) showed that more than a half of rabbit cardiomyocytes demonstrated phasic prolongation of action potential duration in ischemic conditions due to $\mathrm{I}_{\text {to }}$ inhibition. This initial prolongation was followed by the shortening of repolarization presumably due to the

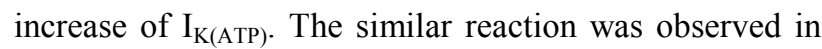
human cells, which makes these observations clinically relevant. The above considerations could explain the varied ARI response to ischemia observed in the control group. As a result, the slight changes in activation and the variable alterations of repolarization caused the RT dispersion in the controls to be statistically unchanged. Therefore, the difference between diabetics and nondiabetics in the repolarization response to ischemia was possibly caused by the different relationships between $\mathrm{I}_{\mathrm{to}}$-dependent prolongation and $\mathrm{I}_{\mathrm{K}(\mathrm{ATP})}$-dependent shortening. This concept remains to be further evaluated.

On the other hand, the diabetics demonstrated a significant though small AT delay in the ischemic zone. This effect was not expressed in the QRS prolongation but could reflect the local changes of the depolarization process, for example, the reduced $\mathrm{I}_{\mathrm{Na}}$ in the diabetic rabbit myocardium (Stables et al. 2014). In contrast to the control group, repolarization durations significantly shortened in the ischemic zone that was associated with the shortening of QT and QTc intervals on the body surface ECG. The difference between the controls and diabetics in the reaction of the repolarization duration to ischemia could be due to the down-regulation of $\mathrm{I}_{\text {to }}$ current in the diabetic animals (Gallego et al. 2009). The inhibition of this current was shown to be responsible for the transient action potential duration prolongation in ischemia (Verkerk et al. 1996). Accordingly, such an effect was not observed in the DM group. The effects of ATs and ARIs oppositely influenced the local RTs thus reducing their change. As the magnitude in milliseconds of the ARI decrease was greater than the AT increase, the boundary RT heterogeneities developed in the diabetic myocardium at ischemia.

Since the diabetic rabbits differed from the normals in their electrophysiological response to ischemia, the abovementioned alterations of ventricular repolarization were likely to be differently expressed in the ECG indices in the control and DM groups. Theoretically, a correlation between the global RT dispersion and the $T_{\text {peak }}-T_{\text {end }}$ interval duration could be expected (Arteyeva et al. 2013) and such a correlation was indeed found, but only in diabetics during the ischemic exposure. This observation at least in part could be explained by the fact that the global RT dispersion in the ischemic diabetic myocardium was significantly correlated with the newly developed boundary RT gradient absent in the control group and the DM group before exposure. Our further observation of the correlation between the $\mathrm{T}_{\text {peak }}-\mathrm{T}_{\text {end }}$ interval duration and the boundary RT gradient in diabetics under ischemia supports the above explanation. Furthermore, it suggests that the measurements of the $T_{\text {peak }}-T_{\text {end }}$ interval could be more effective in the assessment of the local ischemic electrical heterogeneities in a subset of patients with DM as compared to the nondiabetics.

\section{Limitations}

The limitations of the present study concerned at least the short follow-up of DM and the short ischemia exposure. It is not excluded that the longer ones could lead to the more pronounced electrophysiological effects and possibly the spontaneous arrhythmia incidence. Repolarization parameters are often reported to be subject to sex differences. In the present study, we could not specify the effects in males and females. However, the diabetic and control groups did not differ significantly from each other in the male-to-female ratio, and therefore we believe that the observed results could not be 
attributed to gender effects. Anesthesia could have affected the myocardial electrophysiological properties; however, we believe that these effects should be similar in controls and diabetics and should not significantly modify the major findings of the study.

\section{Conclusion}

Thus, the more pronounced ischemia-related prolongation of activation and shortening of repolarization in diabetic animals presumably due to the $\mathrm{I}_{\mathrm{Na}}$ and $\mathrm{I}_{\mathrm{to}}$-down-regulation in DM led to the increase of local electrical inhomogeneities that in turn could be assessed by the $T_{\text {peak }}-T_{\text {end }}$ interval. The findings of the present study suggest that the $T_{\text {peak }}-T_{\text {end }}$ interval can be of different diagnostic utility in different pathological conditions.

\section{Conflict of Interest}

There is no conflict of interest.

\section{Acknowledgements}

The study was supported by the Ural Branch of the Russian Academy of Sciences (Project 13-4-032-KSC) and the Russian Foundation for Basic Research (Grant 14-04-31070, young_a).

\section{References}

ARTEYEVA NV, GOSHKA SL, SEDOVA KA, BERNIKOVA OG, AZAROV JE: What does the T(peak)-T(end) interval reflect? An experimental and model study. J Electrocardiol 46: 296.e1-8, 2013.

BAKTH S, ARENA J, LEE W, TORRES R, HAIDER B, PATEL BC, LYONS MM, REGAN TJ: Arrhythmia susceptibility and myocardial composition in diabetes. Influence of physical conditioning. J Clin Invest 77 : 382-395, 1986.

CARLSSON L, ABRAHAMSSON C, ANDERSSON B, DUKER G, SCHILLER-LINHARDT G: Proarrhythmic effects of the class III agent almokalant: importance of infusion rate, QT dispersion, and early afterdepolarizations. Cardiovasc Res 27: 2186-2193, 1993.

CHO E, RIMM EB, STAMPFER MJ, WILLETT WC, HU FB: The impact of diabetes mellitus and prior myocardial infarction on mortality from all causes and from coronary heart disease in men. J Am Coll Cardiol 40: 954-960, 2002.

CHOW E, BERNJAK A, WILLIAMS S, FAWDRY RA, HIBBERT S, FREEMAN J, SHERIDAN PJ, HELLER SR: Risk of cardiac arrhythmias during hypoglycemia in patients with type 2 diabetes and cardiovascular risk. Diabetes 63: 1738-1747, 2014.

CLEMENTE D, PEREIRA T, RIBEIRO S: Ventricular repolarization in diabetic patients: characterization and clinical implications. Arq Bras Cardiol 99: 1015-1022, 2012.

CORONEL R, DE BAKKER JM, WILMS-SCHOPMAN FJ, OPTHOF T, LINNENBANK AC, BELTERMAN CN, JANSE MJ: Monophasic action potentials and activation recovery intervals as measures of ventricular action potential duration: experimental evidence to resolve some controversies. Heart Rhythm 3: 1043-1050, 2006.

CURIONE M, Di BONA S, AMATO S, TURINESE I, TARQUINI G, GATTI A, MANDOSI E, ROSSETTI M, VARRENTI M, SALVATORE S, BAIOCCO E, MORANO S: Lack of the QTc physiologic decrease during cardiac stress test in patients with type 2 diabetes treated with secretagogues. Acta Diabetol 51: 31-33, 2014.

DZIEWIERZ A, GISZTEROWICZ D, SIUDAK Z, RAKOWSKI T, DUBIEL JS, DUDEK D: Admission glucose level and in-hospital outcomes in diabetic and non-diabetic patients with acute myocardial infarction. Clin Res Cardiol 99: 715-721, 2010.

GALAGUDZA MM, NEKRASOVA MK, SYRENSKII AV, NIFONTOV EM: Resistance of the myocardium to ischemia and the efficacy of ischemic preconditioning in experimental diabetes mellitus. Neurosci Behav Physiol 37: 489-493, 2007.

GALLEGO M, ALDAY A, URRUTIA J, CASIS O: Transient outward potassium channel regulation in healthy and diabetic hearts. Can J Physiol Pharmacol 87: 77-83, 2009.

HEKIMIAN G, KHANDORIDI N, FEUVRAY D, BEIGELMAN PM: Abnormal cardiac rhythm in diabetic rats. Life Sci 37: 547-551, 1985. 
HETLAND M, HAUGAA KH, SARVARI SI, ERIKSSEN G, KONGSGAARD E, EDVARDSEN T: A novel ECG-index for prediction of ventricular arrhythmias in patients after myocardial infarction. Ann Noninvasive Electrocardiol 19: 330-337, 2014.

HOWARTH FC, JACOBSON M, SHAFIULLAH M, LJUBISAVLJEVIC M, ADEGHATE E: Heart rate, body temperature and physical activity are variously affected during insulin treatment in alloxan-induced type 1 diabetic rat. Physiol Res 60: 65-73, 2011.

KUSAMA Y, HEARSE DJ, AVKIRAN M: Diabetes and susceptibility to reperfusion-induced ventricular arrhythmias. J Mol Cell Cardiol 24: 411-421, 1992.

LENGYEL C, VIRÁG L, KOVÁCS PP, KRISTÓF A, PACHER P, KOCSIS E, KOLTAY ZM, NÁNÁSI PP, TÓTH M, KECSKEMÉTI V, PAPP JG, VARRÓ A, JOST N: Role of slow delayed rectifier $\mathrm{K}^{+}$-current in QT prolongation in the alloxan-induced diabetic rabbit heart. Acta Physiol (Oxf) 192: 359-368, 2008.

MAGYAR J, RUSZNÁK Z, SZENTESI P, SZÛCS G, KOVÁCS L: Action potentials and potassium currents in rat ventricular muscle during experimental diabetes. J Mol Cell Cardiol 24: 841-853, 1992.

MATEJÍKOVÁ J, KUCHARSKÁ J, PANCZA D, RAVINGEROVÁ T: The effect of antioxidant treatment and NOS inhibition on the incidence of ischemia-induced arrhythmias in the diabetic rat heart. Physiol Res 57 (Suppl 2): S55-S60, 2008.

MIKI T, TOBISAWA T, SATO T, TANNO M, YANO T, AKASAKA H, KUNO A, OGASAWARA M, MURASE H, SAITOH S, MIURA T: Does glycemic control reverse dispersion of ventricular repolarization in type 2 diabetes? Cardiovasc Diabetol 13: 125, 2014.

MOZOS I: Arrhythmia risk in liver cirrhosis. World J Hepatol 7: 662-672, 2015.

OVECHKIN AO, VAYKSHNORAYTE MA, SEDOVA K, SHUMIKHIN KV, ARTEYEVA NV, AZAROV JE: Functional role of myocardial electrical remodeling in diabetic rabbits. Can J Physiol Pharmacol 93: 245-252, 2015.

PANIKKATH R, REINIER K, UY-EVANADO A, TEODORESCU C, HATTENHAUER J, MARIANI R, GUNSON K, JUI J, CHUGH SS: Prolonged Tpeak-to-Tend interval on the resting ECG is associated with increased risk of sudden cardiac death. Circ Arrhythm Electrophysiol 4: 441-447, 2011.

PISTROSCH F, GANZ X, BORNSTEIN SR, BIRKENFELD AL, HENKEL E, HANEFELD M: Risk of and risk factors for hypoglycemia and associated arrhythmias in patients with type 2 diabetes and cardiovascular disease: a cohort study under real-world conditions. Acta Diabetol 52: 889-895, 2015.

PORTHAN K, VIITASALO M, TOIVONEN L, HAVULINNA AS, JULA A, TIKKANEN JT, VÄÄNÄNEN H, NIEMINEN MS, HUIKURI HV, NEWTON-CHEH C, SALOMAA V, OIKARINEN L: Predictive value of electrocardiographic T-wave morphology parameters and T-wave peak to T-wave end interval for sudden cardiac death in the general population. Circ Arrhythm Electrophysiol 6: 690-696, 2013.

RAVINGEROVÁ T, STETKA R, PANCZA D, ULICNÁ O, ZIEGELHÖFFER A, STYK J: Susceptibility to ischemiainduced arrhythmias and the effect of preconditioning in the diabetic rat heart. Physiol Res 49: 607-616, 2000.

SANJUAN R, BLASCO ML, MARTINEZ-MAICAS H, CARBONELL N, MIÑANA G, NUÑEZ J, BODÍ V, SANCHIS J: Acute myocardial infarction: high risk ventricular tachyarrhythmias and admission glucose level in patients with and without diabetes mellitus. Curr Diabetes Rev 7: 126-134, 2011.

SMETANA P, SCHMIDT A, ZABEL M, HNATKOVA K, FRANZ M, HUBER K, MALIK M: Assessment of repolarization heterogeneity for prediction of mortality in cardiovascular disease: peak to the end of the $\mathrm{T}$ wave interval and nondipolar repolarization components. J Electrocardiol 44: 301-308, 2011.

SPOONER PM: Sudden cardiac death: influence of diabetes. Diabetes Obes Metab 10: 523-532, 2008.

STABLES CL, MUSA H, MITRA A, BHUSHAL S, DEO M, GUERRERO-SERNA G, MIRONOV S, ZARZOSO M, VIKSTROM KL, CAWTHORN W, PANDIT SV: Reduced $\mathrm{Na}^{+}$current density underlies impaired propagation in the diabetic rabbit ventricle. J Mol Cell Cardiol 69: 24-31, 2014.

VAYKSHNORAYTE MA, OVECHKIN AO, AZAROV JE: The effect of diabetes mellitus on the ventricular epicardial activation and repolarization in mice. Physiol Res 61: 363-370, 2012.

VERKERK AO, VELDKAMP MW, VAN GINNEKEN AC, BOUMAN LN: Biphasic response of action potential duration to metabolic inhibition in rabbit and human ventricular myocytes: role of transient outward current and ATP-regulated potassium current. J Mol Cell Cardiol 28: 2443-2456, 1996. 
WANG Y, XUAN YL, HU HS, LI XL, XUE M, CHENG WJ, SUO F, YAN SH: Risk of ventricular arrhythmias after myocardial infarction with diabetes associated with sympathetic neural remodeling in rabbits. Cardiology 121: $1-9,2012$.

ZHANG Y, XIAO J, LIN H, LUO X, WANG H, BAI Y, WANG J, ZHANG H, YANG B, WANG Z: Ionic mechanisms underlying abnormal QT prolongation and the associated arrhythmias in diabetic rabbits: a role of rapid delayed rectifier $\mathrm{K}^{+}$current. Cell Physiol Biochem 19: 225-238, 2007.

ŽÁKOVIČOVÁ E, KITTNAR O, SLAVÍČEK J, MEDOVÁ E, ŠVÁB P, CHARVÁT J: ECG body surface mapping in patients with gestational diabetes mellitus and optimal metabolic compensation. Physiol Res 63 (Suppl 4): S479-S487, 2014. 